\title{
Descrição do Uso e Ocupação da Cabeceira do Rio Jauru (MT) e Caracterização dos Processos de Degradação Ambiental
}

\section{Description of Use and Ocupaton of Headboard of Jauru River (MT) and Processes of the Caracterization of Environmental Degradation}

\author{
Décio Eloi Siebert ${ }^{1}$, Antonio Brandt Vecchiato², Fernando Ximenes de Tavares Salomão² \\ ${ }^{1}$ Curso de Pós-Graduação em Recursos Hídricos, Instituto de Ciências Exatas e da Terra, Universidade Federal de \\ Mato Grosso, Cuiabá. \\ Av. Fernando Correa da Costa s/n -Cidade Universitária. CEP:78060-900. Cuiabá, MT. \\ 2 Departamento de Geologia Geral, Universidade Federal de Mato Grosso, Cuiabá. (brandt@ufmt.br)
}

\begin{abstract}
Recebido: 15/ 02/2013, Aceito: 17/02/2013, Publicado: 08/05/2014
RESUMO - Este trabalho mostra o uso e ocupação do solo na área da cabeceira do rio Jauru (MT), através do mapeamento da evolução do desmatamento no espaço temporal de 30 anos, entre 1979 e 2009, com intervalos de dez anos, a partir de imagens temáticas obtidas dos sensores LANDSAT 2-MSS e LANDSAT 5-TM. Descreve os impactos ambientais existentes e potenciais, e identifica as causas e origem do processo de degradação. O processo de ocupação da Chapada dos Parecis (MT), onde se localiza a cabeceira do rio Jauru, deu-se a partir do ano de 1978, com a chegada dos primeiros colonizadores e intensificou-se na década de 1980, quando ocorreu a derrubada de cerrado nativo para formação de lavouras mecanizadas e áreas de pastagem. A construção da Rodovia BR-364, que ocorreu na década de 1960, foi responsável pelo início da formação dos processos de degradação ambiental existentes na área da cabeceira da nascente principal do rio Jauru (MT). A caracterização efetuada neste trabalho mostra a necessidade do estabelecimento de critérios qualitativos e quantitativos para o planejamento ambiental, a fim de garantir o uso e ocupação do solo nas áreas de influência das cabeceiras de forma mais adequada, não comprometendo a qualidade da água e sua utilização racional para usos múltiplos.
\end{abstract}

Palavras-chave: uso e ocupação do solo, impactos ambientais, áreas de influência

\begin{abstract}
This study shows the land use and occupation in the headwaters area of the river Jauru (MT), by mapping the evolution of deforestation in the timeline of 30 years from 1979 and 2009 at ten years intervals, from thematic images obtained from Landsat-2 MSS and LANDSAT-5 TM 2 sensors. The existing and potential environmental impacts are described identifying causes and origin of the degradation process. The headwaters of the river Jauru is located in the Chapada dos Parecis (MT) whose occupation process took place from the end of 1978 with the arrival of the first settlers and was intensified in the 1980s, with the deforestation of the native savannah for the formation of mechanized farming and grazing areas. The construction on highway BR-364, which occurred in the 1960s, was responsible for the beginning of environmental degradation in the headwater of the River Jauru. The characterization shows the need to establish qualitative and quantitative criteria for environmental planning, to ensure appropriate land use and occupation in the areas of influence of headwaters, in order to prevent compromising water quality and assure its rational utilization for multiple uses.
\end{abstract}

Key-words: land use, environment impacts, influence areas

\section{INTRODUÇÃO}

O modelo de desenvolvimento que prioriza aspectos econômicos tem provocado $\mathrm{o}$ aumento da degradação ambiental e o crescimento da pobreza e das desigualdades sociais (GIDDENS, 1991).

Apoiado no argumento da necessidade de aumentar a produção de alimentos e de criar a infra-estrutura necessária para sua viabilização, e também para propiciar o desenvolvimento e crescimento do país, observa-se alguns equívocos na implementação desse modelo. Podendo-se apontar como exemplo, a construção da Rodovia BR-364 na Chapada dos Parecis na década de 1960 e mais recentemente, já nos anos 2000, a construção da Rodovia MT-480 (Figura 1). 
Citação: Siebert D. E., Vecchiato A. B. e Salomão F. X. T. Descrição do Uso e Ocupação da Cabeceira do Rio Jauru (MT) e Caracterização dos Processos de Degradação Ambiental. E\&S - Engineering and Science, (2014), 1:1.

Figura 1 - Foto aérea da rodovia MT-480 em fase de construção. Fonte: Paraplano, 2007.

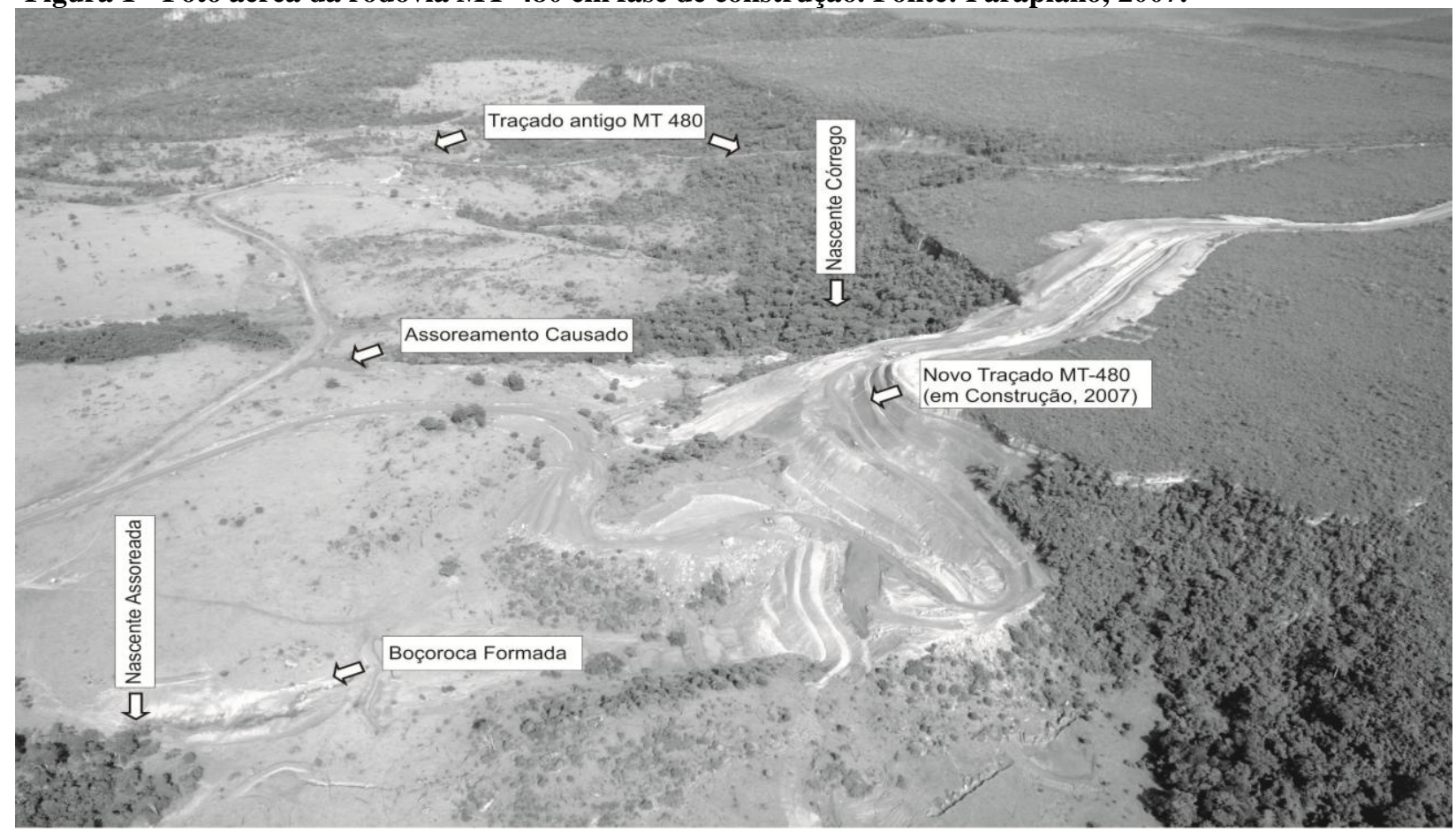

O século $\mathrm{XX}$, e também o início do século XXI, é marcado por grandes avanços tecnológicos alcançados pelo homem, no entanto isso tem ocasionado mudanças significativas na paisagem natural e consequentemente, tem causado preocupações no tocante à qualidade do ambiente (BARTH, 1997). O homem tem se mostrado um dos principais agentes modificadores da paisage natural, o que muitas vezes têm desencadeado processos de degradação ambiental de difícil reversão. Lal (1988) fez uma estimativa sobre os sedimentos lançados pelos rios nos oceanos, que passaram de 10 bilhões de toneladas por ano, antes da intervenção do homem, para um valor entre 25 e 50 bilhões após a introdução da agricultura intensiva, pastagens e outros usos do solo.

O processo de construção e manutenção da Rodovia BR-364 e a implantação de atividades de agricultura e pecuária na região da cabeceira do rio Jauru (MT), a exemplo de outras regiões do Estado de Mato Grosso, promoveu a geração de emprego e renda, no entanto deixou marcas negativas para o meio ambiente.

Desta forma, este trabalho visa apontar as implicações decorrentes do uso e ocupação do solo na área de contribuição da cabeceira da nascente principal do rio Jauru. Bem como, identificar e descrever os impactos ambientais potenciais e existentes na área em questão, que afetam de forma direta ou indireta a qualidade da água, e funcionamento hidrológico, com reflexos sobre a biodiversidade do Pantanal, podendo também comprometer o seu potencial de geração de energia elétrica, através do assoreamento do leito do rio e dos reservatórios dos empreendimentos construídos. 


\section{ÁREA DE ESTUDO}

A área estudada compreende a cabeceira das nascentes principais do rio Jauru e seu entorno, correspondente à bacia de contribuição. Tem sua nascente principal localizada nas coordenadas geográficas $\mathrm{S} 14^{\circ}$ 30' 02" e W 58 29' 53", na Chapada dos Parecis, no município de Tangará da Serra, a aproximadamente 370 quilômetros de Cuiabá, Estado de Mato Grosso.

$\mathrm{O}$ rio Jauru, que é um dos principais afluentes da margem direita do rio Paraguai, faz parte do chamado Arco das Nascentes do Pantanal em Mato Grosso, como descrito no Relatório Anual WWF-Brasil (2008), e é formado também pelos rios Cabaçal, Bugres, Sepotuba, Paraguai, Cuiabá e São Lourenço, principalmente.

O Arco das Nascentes contorna a Bacia do Alto Paraguai nos seus limites com as bacias hidrográficas do Tocantins-Araguaia e Amazônica, em forma de semicírculo. Vai de Rondonópolis, passando por Campo Verde, Rosário Oeste, Diamantino, Nova Marilândia, Tangará da Serra, Reserva do Cabaçal, até Cáceres. Segundo o Relatório Anual WWFBrasil (2008), o Arco das Nascentes do Pantanal em Mato Grosso, juntamente o rio Taquari e rio Coxim no Mato Grosso do Sul é responsável pelo fornecimento de $70 \%$ da água que corre para o Pantanal.

A área de estudo está inserida regionalmente na unidade geomorfológica denominada de Planalto dos Parecis, que se caracteriza por terrenos ligeiramente aplainados e com pequeno aprofundamento de drenagem, configurando colinas amplas e superfícies rampeadas.

Segundo o mapa de solos da SEPLAN-MT (2007), predominam na região onde se insere a área objeto deste estudo, dois tipos de solos. Nas partes mais altas e planas da Chapada dos Parecis, são encontrados Latossolos Vermelho-Escuro e Vermelho Amarelo. Na área do entorno da nascente e de contribuição da cabeceira, os solos são classificados como Neosolos Quartzarênicos.
O rio Jauru, além de ser um importante tributário do Pantanal Mato-grossense, possui também um grande potencial de geração de energia elétrica. No sentido de montante a jusante do rio Jauru encontra-se a $\mathrm{PCH}$ Antonio Brennand, com capacidade de geração de 20 MVA, a PCH Ombreiras com 26 MVA, a UHE Jauru com 120 MVA, a PCH Indiavaí com 28 MVA, a PCH Salto Jauru com 20 MVA e a PCH Figueirópolis, que se encontra em fase de construção.

\section{MATERIAL E MÉTODOS}

O levantamento de uso e ocupação das terras da região da Cabeceira do rio Jauru, foi realizado através da utilização de técnicas de sensoriamento remoto, compreendendo $\mathrm{o}$ processamento digital de imagens de satélite, interpretação de fotografias aéreas, coleta de dados no campo e entrevistas com proprietários rurais.

Os procedimentos metodológicos utilizados basearam-se no Manual Técnico de Uso do Solo editado pelo IBGE (2006), permitindo a organização de etapas de trabalho.

Para a determinação dos períodos de avaliação, convencionou-se a realização de observações em imagens de satélite em espaços temporais que apresentassem alterações significativas da paisagem, a partir de um marco inicial onde as condições de cobertura vegetal nativa fossem de poucos sinais de desflorestamento. Foi escolhido o período de 1979 a 2009, e as avaliações realizadas em espaços de 10 anos. As características das imagens estão descritas na Tabela 1.

\begin{tabular}{lccl}
\hline Satélite & Anos & $\begin{array}{c}\text { Órbita/ } \\
\text { Ponto }\end{array}$ & Data \\
\hline Landsat 2 & 1979 & 245 & $25 / 05 / 1979$ \\
Landsat 5 & 1989 & 228 & $29 / 08 / 1989$ \\
Landsat 5 & 1999 & 228 & $24 / 07 / 1999$ \\
Landsat 5 & 2009 & 228 & $30 / 04 / 2009$ \\
\hline
\end{tabular}

Tabela. 1. Órbita/ponto e dados das imagens de satélite empregados no estudo de uso e ocupação do solo da cabeceira do rio Jauru.

A interpretação das imagens orbitais foi desenvolvida com o software ERDAS 
Imagine versão 8.5. A geração do modelo digital de elevação hidrograficamente consistente e o mapeamento das áreas da cabeceira do rio Jauru foram realizados com o software ArcGIS, versão 9.2.

Foram realizadas cinco visitas à área de estudo, para coleta de pontos e registro fotográfico das várias feições ocorrentes para subsidiar a classificação das imagens de satélites.

Foram também utilizadas informações e fotografias de visitas realizadas em períodos anteriores a agosto de 2007. Em março de 2007 foi realizado, com apoio do WWFBrasil, um levantamento aerofotogramétrico georreferenciado da área de contribuição da cabeceira do rio Jauru.

Foram coletadas as coordenadas geográficas das áreas dos processos erosivos, da nascente e em locais do leito do rio Jauru. Foi efetuado registro fotográfico aéreo e do nível do solo, para descrever melhor a paisagem encontrada na área de estudo. Os pontos foram usados na correção geométrica, na aferição das informações obtidas da classificação da imagem e na caracterização das classes fisionômicas existentes na área de estudo.

Para elaborar o histórico do uso e ocupação do solo foram utilizadas imagens digitais MSS/LANDSAT 2 de 1979 (maio) e TM/LANDSAT 5 de 1989 (agosto), 1999 (julho) e 2009 (abril).

A primeira imagem corrigida foi à correspondente ao ano de 1979, por estar próxima do início da colonização da região do entorno da área de estudo.

No processamento digital das imagens TM foram utilizadas as bandas espectrais 3, 4 e 5, de intervalo espectral 0,63-0,69 $\mu \mathrm{m}, 0,76-0,90$ $\mu \mathrm{m}$ e $1,55-1,75 \mu \mathrm{m}$. Estas foram processadas de forma a elaborar a composição colorida, associando as bandas 3, 4 e 5 aos canais azul, verde e vermelho, respectivamente.

As imagens das diferentes épocas foram classificadas em cinco classes para todos os anos: Vegetação Nativa, Campo Sujo, Agropastoril, Cascalheira e Erosões. No ano de 1999 foi avaliada também uma área de Queimada (Incêndios) e no ano de 2009 o Assoreamento do rio Jauru no trecho inicial do seu leito.
A escolha desses termos para representar as classes fisionômicas presentes na área de estudo, deve-se ao ajuste da imagem em função do tamanho da área e à necessidade de enquadramento de todas as formas de alteração ocorridas nesse local. Assim o termo Vegetação Nativa corresponde às formações de Savana Arborizada (cerrado), Savana Arborizada com Mata de Galeria, incluindo nessa categoria as Matas Ciliares. O termo Campo Sujo compreende os campos com maior ou menor intensidade de arbustos e subarbustos. O termo Agropastoril engloba todas as formas de uso para agricultura e pecuária de corte presentes na área de estudo. O termo Cascalheira representa os locais onde houve retirada de material de empréstimo para utilização na Rodovia BR-364. O termo Erosões corresponde a todos os processos erosivos observados na área de estudo, ravinas e boçorocas e o termo. Assoreamento caracteriza o material carreado dos processos erosivos para a área de pastagem, localizada ao sul da primeira cascalheira identificada já no ano de 1979, e para o leito do rio Jauru próximo da sua nascente.

Foram realizadas entrevistas com proprietários rurais da área de estudo e do seu entorno, utilizando para tanto um questionário previamente elaborado.

As entrevistas tiveram como objetivo a busca de informações complementares sobre o início do período de ocupação e sua evolução, na região da Chapada dos Parecis, nas proximidades da cabeceira do rio Jauru, na margem sul da Rodovia BR-364.

Com base nas informações obtidas através das entrevistas, procedeu-se uma nova interpretação das imagens de satélite, com objetivo de enriquecer os dados levantados.

\section{RESULTADOS E DISCUSSÃO}

Através da interpretação das imagens de satélite foi possível identificar o período de início da ocupação e sua evolução na área de estudo, localizada na cabeceira da nascente principal do rio Jauru.

Conforme descrito na Tabela 02, observouse que até o ano de 1979 a área desmatada no interior da cabeceira do rio Jauru resumia-se basicamente a 6,11 hectares, correspondendo 
a um local de retirada de material de empréstimo (Cascalheira), localizado na parte norte da área de estudo e que representa $0,39 \%$ da área estudada. Foram identificadas também áreas de Vegetação Nativa em 352,28 hectares $(22,60 \%)$ e de Campo Sujo em $1.200,10$ hectares $(77,01 \%)$.

\begin{tabular}{lll}
\hline $\begin{array}{l}\text { Classes } \\
\text { Fisionômicas }\end{array}$ & $\begin{array}{l}\text { Área } \\
\text { (ha) }\end{array}$ & Percentual (\%) \\
\hline $\begin{array}{l}\text { Vegetação } \\
\text { Nativa }\end{array}$ & 352,28 & $22,60 \%$ \\
Campo Sujo & $1.200,10$ & 77,01 \\
Cascalheira & 6,11 & 0,39 \\
\hline
\end{tabular}

Tabela 2. Distribuição das classes fisionômicas em 1979 na área da cabeceira do rio Jauru

Através da análise da Tabela 03, observase que houve mudanças nas áreas ocupadas por todas as classes fisionômicas na cabeceira do rio Jauru, no espaço temporal de 10 anos. Percebe-se que ocorreu a formação das primeiras áreas de lavouras e pastagens (Agropastoril), e como consequência a supressão de Vegetação Nativa e de Campo Sujo, e concomitantemente a formação de Processos Erosivos. Também foi possível observar o aumento das áreas de retirada cascalho. No período compreendido entre o ano de 1979 e o ano de 1989, a área de Vegetação Nativa que era de 352,28 hectares e representava $22,60 \%$ da área total estudada, foi reduzida para 127,69 hectares $(8,19 \%)$, o que significa uma diminuição 63,25\%. A área de Campo Sujo, que na avaliação anterior ocupava 1.200,10 hectares e representava $77,01 \%$ da área total, também teve sua área reduzida para 989,59 hectares $(63,50 \%)$ o que em termos percentuais representa uma redução de $17,54 \%$. Nas áreas onde foi registrado o desflorestamento de Vegetação Nativa e Campo Sujo, observa-se a formação das primeiras áreas de agricultura e pecuária (Agropastoril) e a criação de um novo local de retirada de material de empréstimo (Cascalheira). Nesse decênio, houve a formação de 406,98 hectares de áreas de lavoura e pastagem (Agropastoril), o que representa $26,11 \%$ da área total. Nesse período percebeu-se também a formação de 21,58 hectares de Processos Erosivos na forma de erosão linear, que representam 1,3\% da área de estudo.

As ocorrências erosivas foram identificadas no interior da cabeceira e em seu entorno, onde se observam predomínio de solos arenosos (Neosolos Quartzarênicos), que, segundo Salomão (1999), são muito erodíveis, e desde que desmatados, manifestase a desagregação e liberação das suas partículas pelo impacto das gotas d'água da chuva e pelo escoamento superficial, desenvolvendo erosão laminar e linear.

De acordo com Bertol et al. (1989), "a cobertura (viva ou morta) do solo pode promover redução nas perdas de solo de até $90 \%$ e na velocidade da enxurrada de até $62 \% "$.

Observando o mapa temático elaborado a partir de imagem de satélite do ano de 1989 e os dados apresentados na Tabela 3, e considerando que o período de análise é de apenas 10 anos e coincide com a época de supressão do cerrado e da formação de áreas lavouras e pastagem, e também com a criação de mais um local de retirada de material de empréstimo (cascalho), pode-se considerar que foram essas ações antrópicas a causa principal da formação dos processos erosivos.

Foi possível observar que os processos erosivos lineares tiveram seu início em dois locais de retirada de cascalho, situados na porção nordeste da área de estudo.

\begin{tabular}{lll}
\hline $\begin{array}{l}\text { Classes } \\
\text { Fisionômicas }\end{array}$ & $\begin{array}{l}\text { Área } \\
\text { (ha) }\end{array}$ & $\begin{array}{l}\text { Percentual } \\
(\%)\end{array}$ \\
\hline Vegetação Nativa & 127,69 & 8,19 \\
Campo Sujo & 989,59 & 63,50 \\
Cascalheira & 12,64 & 0,81 \\
Agropastoril & 406,98 & 26,11 \\
Erosões & 21,58 & 1,38
\end{tabular}

Tabela 3. Distribuição das classes fisionômicas em 1989 na área da cabeceira do rio Jauru

$\mathrm{Na}$ avaliação qualitativa e quantitativa do mapa temático do ano de 1999 e dos dados obtidos e apresentados na Tabela 4 respectivamente, observa-se novas mudanças nas áreas ocupadas pelas classes fisionômicas relacionadas ao processo de antropização da cabeceira do rio Jauru, nesse período de 10 anos. Percebeu-se que ocorreu um aumento 
das áreas de lavouras e pastagens, e da mesma forma que no período anterior analisado, a supressão de Vegetação Nativa e de Campo Sujo. Observa-se também o aumento da área afetada pelos Processos Erosivos. Na imagem do ano de 1999 foram identificadas também queimadas em áreas anteriormente ocupadas por cerrado e campo.

No período que abrange o decênio entre o ano de 1979 e o ano de 1989, houve o aumento das áreas de lavouras e pastagens (Agropastoril) em 32,72\%, passando de 406,98 hectares para 540,14 hectares. Houve também nesse período um crescimento acentuado dos Processos Erosivos em $75,39 \%$, passando de 21,58 hectares para 37,85 hectares. Outro processo de degradação observado no ano de 1999 foi o de queimadas em 105,38 hectares, da porção norte/noroeste da área de estudo, especialmente no interior da reserva indígena.

Concomitantemente com aumento da formação de lavouras e pastagens e dos processos erosivos, assim como das queimadas registradas no ano de 1999, observa-se novamente nesse período, a redução das áreas de Vegetação Nativa. O decréscimo dessa classe fisionômica foi de $24,88 \%$ em relação ao período anterior, ficando a área limitada a 95,92 hectares. Da mesma forma, a área de Campo Sujo também sofreu redução de $22,54 \%$, passando de 989,59 hectares para 766,55 hectares. Nesse período não houve aumento nas áreas das Cascalheiras.

Foi possível perceber similaridade entre o comportamento dos fatores analisados nesse período, em relação ao período anterior de 1989 a 1999, no tocante ao aumento dos processos de degradação, associados ao aumento das áreas de lavouras e pastagens e da redução da cobertura vegetal nativa. Observou-se ainda a ausência de medidas preventivas ou corretivas em relação aos processos erosivos existentes.

\begin{tabular}{lll}
\hline $\begin{array}{l}\text { Classes } \\
\text { Fisionômicas }\end{array}$ & $\begin{array}{l}\text { Área } \\
\text { (ha) }\end{array}$ & Percentual (\%) \\
\hline $\begin{array}{l}\text { Vegetação } \\
\text { Nativa }\end{array}$ & 87,03 & 5,58 \\
Campo Sujo & 734,74 & 47,15 \\
Cascalheira & 12,64 & 0,81 \\
Agropastoril & 631,74 & 40,53 \\
Erosões & 57,60 & 3,70 \\
Assoreamento & 34,74 & 2,23 \\
\hline
\end{tabular}

Tabela 4. Distribuição das classes fisionômicas em 1999 na área da cabeceira do rio Jauru

O período de 1999 a 2009 é marcado por aumento substancial da ocupação agropastoril e dos processos erosivos, conforme atesta a Tabela 5.

\begin{tabular}{llc}
\hline $\begin{array}{l}\text { Classes } \\
\text { Fisionômicas }\end{array}$ & $\begin{array}{l}\text { Área } \\
\text { (ha) }\end{array}$ & $\begin{array}{c}\text { Percentual } \\
(\%)\end{array}$ \\
\hline Vegetação Nativa & 95,92 & 6,15 \\
Campo Sujo & 766,55 & 49,19 \\
Cascalheira & 12,64 & 0,81 \\
Agropastoril & 540,14 & 34,66 \\
Erosões & 37,85 & 2,43 \\
Incêndios & 105,38 & 6,76 \\
(Queimadas) & & \\
\hline
\end{tabular}

Tabela 5. Distribuição das classes fisionômicas em 2009 na área da cabeceira do rio Jauru

A ocorrência erosiva no interior no interior da cabeceira, que teve seu início registrado na década de 1980, evoluiu em extensão, transformando-se em boçoroca e atingindo o leito do rio Jauru, destruindo por assoreamento área de mata ciliar, nas proximidades da sua nascente. Percebeu-se também a formação de novas áreas de lavoura e pastagem.

Nesse período houve novamente um aumento significativo dos Processos Erosivos em 52,18\%. Se incluirmos nessa avaliação a área degradada por assoreamento de 34,74 hectares tem-se $\mathrm{o}$ aumento das áreas degradadas nesse período de $143,96 \%$, o que representa $5,73 \%$ da área da cabeceira do rio Jauru. Observa-se que o aumento das áreas de lavouras e pastagens foi de $16,96 \%$, chegando a 631,74 hectares, o que representa $40,53 \%$ da área total estudada. Observa-se ainda a supressão da área de Vegetação Nativa em mais 8,89 hectares, restando apenas $5,58 \%$ 
dessa classe fisionômica no ano de 2009, na área estudada. A área de Campo sujo ficou limitada a $47,15 \%$ da área total.

$\mathrm{O}$ processo de degradação observado na Cabeceira do rio Jauru, conforme Tabela 5, ocupava em abril de 2009 uma área de 104,98 hectares.

\section{CONCLUSÃO}

Este estudo mostrou que os métodos utilizados na implantação da infra-estrutura de transporte rodoviário, mais especificamente na construção de rodovias, não são adequados no tocante à preservação dos recursos naturais.

Muitos aspectos relevantes desse processo não têm sido observados, como por exemplo, a recuperação dos locais de retirada de material de empréstimo usados na construção e manutenção das rodovias, e a contenção das águas pluviais.

No caso específico da cabeceira do rio Jauru, pode-se associar essas ações antrópicas de remoção da camada superficial do solo ao início da formação de ravinas no interior da cabeceira.

Com a retirada da cobertura vegetal nativa para implantação de áreas de lavoura e pastagens, os processos erosivos evoluíram ao longo de mais de 20 anos, culminando com a formação de boçorocas.

Outra conseqüência è o carreamento de grande volume de sedimentos para o leito e para área de preservação permanente do rio Jauru, causando o assoreamento das áreas de preservação permanente nas margens do rio Jauru e no seu leito.

Os resultados obtidos com o estudo realizado na cabeceira do rio Jauru, mostraram a necessidade de mudança no sistema de uso e ocupação do solo de áreas que apresentam grande fragilidade, e quando utilizadas de maneira inadequada podem ser palco de intensos processos de degradação.

Através desse estudo também foi possível observar a necessidade do aprofundamento das discussões sobre a legislação ambiental, no tocante à proteção e preservação de nascentes e áreas de cabeceiras.

\section{REFERÊNCIAS BIBLIOGRÁFICAS}

ASSOCIAÇÃO BRASILEIRA DE NORMAS TÉCNICAS, 2002, NBR14724 Normas para apresentação de trabalhos acadêmicos. 6p.válida a partir de 29.09.2002.

BARTH, FT. Modelos para o gerenciamento de recursos hídricos. São Paulo: Nobel/ABRH, 1987.

BIGARELLA, J. J. et al. Estrutura e origem das paisagens tropicais e subtropicais. v. 3. Florianópolis: EdUFSC, 2003, p. 1.436.

BRASIL. Lei $n^{\circ} 4.771$, de 15 de setembro de 1965.Institui o novo Código Florestal. Diário Oficial da União, Brasília, DF, de 16. set. 1965.

BRASIL. Lei 9.433, de 08. jan. 1997. Institui a Política Nacional de Recursos Hídricos, Cria o Sistema Nacional de Gerenciamento dos Recursos Hídricos, regulamenta o inciso XIX do artigo 21 da CF, e altera o artigo 1 da Lei 8.001de 13.03.1990 que modificou a Lei 7.990, de 28.12.1989. Diário Oficial da República Federativa do Brasil, Brasília, DF，09. jan.1997.Disponível em: <http: // www.mma.gov.br/> Acesso em: 04.02.2009

BRASIL. Ministério do Meio Ambiente dos Recursos Hídricos e da Amazônia Legal (Brasília, DF). Plano de Conservação da Bacia do Alto Paraguai (Pantanal) PCBAP: análise integrada e prognóstico da Bacia do Alto Paraguai. Brasília, 1997. 369 p., anexos. Programa Nacional do Meio Ambiente. Projeto Pantanal. http://www.mre.gov.br/

BRITZKE, B. Estudo florístico no entorno da nascente do rio Jauru-MT para fins de gestão ambiental - Tangará da Serra-MT, 2006. Monografia (Graduação) Unemat. 52f.,.

CHRISTOFOLETTI, A. Geomorfologia. São Paulo: Edgard Blucher, 1980.

COUTINHO. C. A. Segmentação e Classificação de imagens landsat-tm para o 
mapeamento dos usos da terra na região de Campinas. SP. 1997. Dissertação

(Mestrado em Ciências). Universidade de São Paulo. Campinas. 1997.

GIDDENS, A. As conseqüiências da modernidade - São Paulo, Editora UNESP, 1991,180p.

GUERRA, A.J.T... [et al.] Geomorfologia e meio ambiente - Rio de Janeiro: Bertrand Brasil,1996. P 291;323.

IPT - Instituto de Pesquisas Tecnológicas do Estado de São Paulo S.A. Controle de erosão urbana. DAEE-IPT, São Paulo, 1989.

LAL, R. Soil erosion by wind and water: problems and prospects. In: LAL, R (Ed). Soil erosion research methods. Iowa: Soil and Water Conservation Society, 1988.p.1-6.

MINISTÉRIO DO MEIO AMBIENTE / Secretaria de Recursos Hídricos, 2006, Caderno da região hidrográfica do Paraguai - Brasília: MMA, 2006. 140p

MINISTÉRIO DO MEIO AMBIENTE / Secretaria de Recursos Hídricos, 2006, Plano Nacional de Recursos Hídricos. Síntese Executiva - Brasília: MMA, 2006. 135p

MINISTÉRIO DAS MINAS E ENERGIA, 1982. Projeto RADAMBRASIL, Folha SD 21 CUIABÁ. Rio de Janeiro, 1982

MOREIRA, M. A. Fundamentos do sensoriamento remoto e metodologias de aplicação. São José dos Campos: Instituto Nacional de Pesquisas Espaciais (INPE), 2001. 250 p.

NIMER, E.; BRANDÃO ,A. M. P. M.. 1989. Balanço hídrico e clima da região dos cerrados.IBGE, Rio de Janeiro, 128p.

PAISANI, J. C.; OLIVEIRA, M. A. T. Dinâmica da área de contribuição para a formação de escoamento superficial saturado - cabeceira de drenagem da
Colônia Quero-Quero - Palmeira (PR). Geociências, v. 18, n. 2, p. 261-284, 1999.

PICHLER, E. Boçorocas. Boletim da Sociedade Brasileira de Geologia, v. 4, $\mathrm{n}^{\circ}$ 1, p. 3-16, 1953.

REBOUÇAS, A.C. ; BRAGA, B., TUNDISI, J.G. Águas doces no Brasil: capital ecológico, uso e conservação - 3. ed, - São Paulo: Escrituras Editora, 2006

ROHDE, G.M. Geoquímica Ambiental e Estudos de Impacto; - 2.ed. - São Paulo: Signus Editora, 2004. p.83

SALATI, Eneas et al. Temas ambientais relevantes. 20 (56): 107-27, São Paulo: Editora USP, 2006.

SALOMÃO, F.X.T. Controle e Prevenção dos Processos Erosivos In: GUERRA, A.T., SILVA, A. S., B., BOTELHO, Rosângela Garrido Machado (org). Erosão e Conservação dos Solos - Conceitos, Temas e Aplicações. Rio de Janeiro: Bertrand Brasil,1999.

SERIGATTO, E. M. Delimitação automática das áreas de preservação permanente e identificação dos conflitos de uso da terra na bacia hidrográfica do rio Sepotuba-MT. Viçosa, 2006. Tese (Doutorado). Universidade Federal de Viçosa. $188 \mathrm{p}$.

SOUZA, C.R.G. ; SUGUIO, K. ; OLIVEIRA, A.M.S. ; OLIVEIRA, P.E. Quaternário do Brasil - Ribeirão Preto: Holos, Editora, 2005. 382p.

TUCCI, C.E.M. ; SILVEIRA, A.L.L. Hidrologia: ciência e aplicação - 4.ed. Porto Alegre: Editora da UFRGS/ABRH, 2007.

WWF-Brasil. Relatório Anual 2008 Brasília: Athalaia Gráfica , 2008. 87p. 